\section{My life with NF1}

The index of the most recent edition of the standard UK paediatric textbook refers the reader to 10 pages featuring neurofibromatosis. Reading them one learns about the diagnostic criteria, neuroimaging features, genetics, and the special features of eye and skin involvement but not about on how patients might feel. Perhaps that is hardly the mission of a clinical and academic text. This month Miss Beadle fills the gap by reminding us what it is like for her.

M y memory isn't very good, but from what I can remember of my childhood, I was very quiet and withdrawn and although I read a lot, I didn't retain much. My teachers all thought I was lazy and not willing to learn. Even I couldn't understand why it took me so long to grasp simple things. Then I had my first epileptic fit when I was 6.

I remember feeling scared because of the way my body felt after I had a seizure, and confused because I was also so sleepy and my mouth tasted bitter. It wasn't until much later that I found out my parents put a phenobarbitone tab in my mouth during my seizure.

Life continued in much the same way and I became more and more withdrawn and didn't do much socialising, preferring to be in my own private Idaho. As the years went by, my spine slowly started to curve and multiple birthmarks (cafe-au-lait) were discovered all over my body. The doctors diagnosed scoliosis and von Recklinghausen's disease (NFl) as it was then known.

None of us had ever heard anything about the condition, and as far as we were aware, no other family member had it. At 13, I had a major operation and a Harrington's rod was attached to my spine. In medical terms, the operation was deemed a success, but the girl

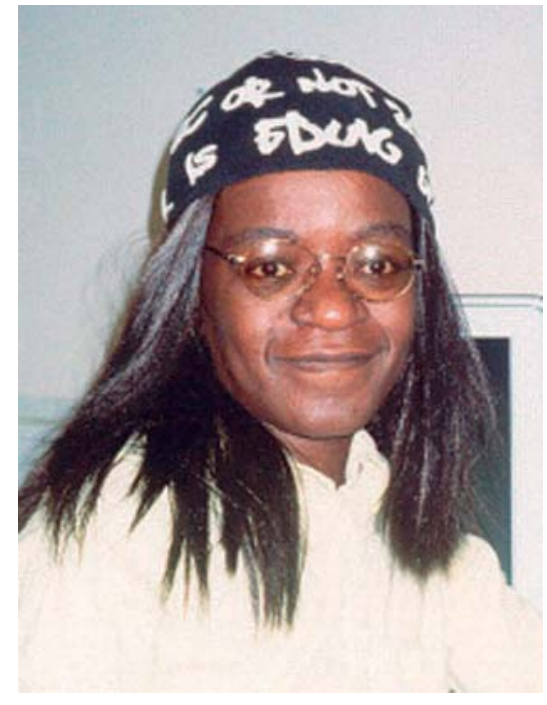

on me as a teenager. Even today, the rational me cannot move past it.

As I got older I got quieter and more withdrawn. I was also incredibly naive and also not trusting. My fibromas continued to grow and with them, my insecurities.

Regardless of the amount of family and friends, I still felt alone. My confidence continued to plummet and I couldn't see a light at the end of a tunnel. In my dream world, I was constantly falling into a dark and never ending abyss.

I got to the age where I discovered relationships. Because of my insecurities, I let my heart rule my head, and ended up getting hurt.

They say, "Courage can only be felt by those who are afraid". I concur with this statement. I am afraid. I'm afraid of

in the mirror looking back at me was still lean.

In private, I felt like I was on a slippery slope, heading straight for depression, but when I was with family and friends, they saw what they wanted to see-a happy, always contented teenager.

Shortly after the operation, fibromas started to appear all over my body. At first, it was hardly noticeable, but as time went on, more and more lumps showed up on my body. I became "quietly" suicidal. I began to think of different ways to kill myself. It would have been so easy. But the one thing that stopped me from actually attempting suicide, was realising what I'd be doing to my family. A family that devoted a lot of time and care to make me feel better, to include me, to make sure that I wasn't treated different or to make sure I didn't feel different from my siblings.

I was sent to see a "psychiatrist" and I told him about my feelings of depression. He asked to see my "problem" and I showed him my chest. All he could say was, "Oh I can see what you mean. I see why you're depressed". Those words had a long lasting, devastating effect living and dying with NF. I'm afraid of being alone. I'm afraid of being ridiculed and laughed at. I'm afraid of being me. My friends would say I need the courage to move past this and accept myself for who I am. Well I do accept myself, I just don't think anyone else will (other than those close to me).

For me, the psychological problems are far more damaging than the physical ones but although I hate having NF, I'm grateful for its presence in my life, because I strongly feel that were it not for NF, then I wouldn't be the person I am today. Welcoming and non-judgemental towards people with other disabilities, abilities, races, and sexualities.

Today, I still have a few insecurities, but I'm no longer depressed or suicidal. If I do get dark days, it doesn't take me long to snap out of it. I'm on the road to psychological recovery, I'm happy, contented, accepting of myself and I embrace life.

C M Beadle

Correspondence to: Dr H Marcovitch, Syndication Editor, BMJ Publications; hmarcovitch@btinternet.com 